\section{For-profit versus not-for-profit provision of end-stage renal disease care}

It has been proposed that cost-efficiency measures in for-profit hemodialysis units might result in poor quality of care; early studies reported that mortality rates were higher in for-profit units than in not-for-profit units. Now, results of a large retrospective analysis of contemporary data indicate that for-profit dialysis centers actually have better outcomes for conventional endstage renal disease performance measures than not-for-profit units.

The analysis included 46,600 hemodialysis patients from 3,703 centers in the US. Compared with patients in not-for-profit facilities $(n=15,085)$, patients in for-profit centers $(n=31,515)$ were older $(P=0.002)$ and more likely to be black $(P<0.0001)$, female $(P=0.002)$, diabetic $(P<0.0001)$ and hypertensive $(P<0.0001)$. After 1 year of follow-up, patients in for-profit and not-for-profit units had similar mortality rates $(19.4 \%$ and $18.6 \%$, respectively). In multivariate analyses, however, patients in forprofit units had a greater risk of mortality than those in not-for-profit units (hazard ratio 1.09; $P=0.004)$. The magnitude of this association $\left(\chi^{2}=8.5\right)$ was much less than that between mortality and conventional risk factors, such as age $\left(\chi^{2}=1,205.0 ; P<0.0001\right)$ and serum albumin level $\left(\chi^{2}=861.3 ; P<0.0001\right)$.

Unexpectedly, compared with those in notfor-profit centers, more patients in for-profit units met established benchmarks of hemodialysis care, such as a urea reduction ratio of $\geq 65 \%$ and a hematocrit of $\geq 33 \%(P<0.0001$ for both). Patients in for-profit centers also had higher levels of transferrin saturation and serum albumin than patients in not-for-profit facilities $(P<0.0001$ for both).

Original article Szczech LA et al. (2006) Associations between CMS's Clinical Performance Measures project benchmarks, profit structure, and mortality in dialysis units. Kidney Int 69: 2094-2100

\section{Low-level lead exposure is a risk factor for progressive diabetic nephropathy}

Researchers in Taiwan have found that chronic low-level environmental lead exposure accelerates progression of diabetic nephropathy in patients with type 2 diabetes. Deterioration of renal function in patients with body lead burdens near the upper limit of normal can be slowed with lead chelation therapy, according to the results of the small study.

Patients with diabetic nephropathy $(n=87)$ were observed for 12 months. In longitudinal multivariate analyses, glomerular filtration rate declined by $7.2 \mathrm{ml} / \mathrm{min} / 1.73 \mathrm{~m}^{2}$ of body surface area with each $0.48 \mu \mathrm{mol}(100 \mu \mathrm{g})$ increment in body lead burden $(P<0.0001)$, and by $0.56 \mathrm{ml} / \mathrm{min} / 1.73 \mathrm{~m}^{2}$ of body surface area with each $0.04 \mu \mathrm{mol} / \mathrm{l}(1 \mu \mathrm{g} / \mathrm{dl})$ increment in blood lead level $(P=0.0280)$.

Patients with a body lead burden of between $0.39 \mu \mathrm{mol}(80 \mu \mathrm{g})$ and $2.90 \mu \mathrm{mol}(600 \mu \mathrm{g})$ plus a serum creatinine level of between $132.6 \mu \mathrm{mol} / \mathrm{l}$ $(1.5 \mathrm{mg} / \mathrm{dl})$ and $344.8 \mu \mathrm{mol} / \mathrm{l}(3.9 \mathrm{mg} / \mathrm{dl} ; n=30)$ were randomized $1: 1$ to receive weekly $2 \mathrm{~h}$ infusions of calcium disodium ethylenediaminetetraacetic acid $(1 \mathrm{~g})$ or placebo. Chelation therapy was stopped when body lead burden was less than $0.29 \mu \mathrm{mol}(60 \mu \mathrm{g})$. Twelve months after cessation of therapy, the rate of glomerular filtration rate decline was slower in the chelation group than in the control group $(5.0 \mathrm{ml} / \mathrm{min} /$ year vs $11.8 \mathrm{ml} / \mathrm{min} /$ year; $P=0.0084)$. No adverse effects were reported.

Environmental lead exposure is a worldwide problem; the general populations of Europe and the US have mean blood lead levels of $0.55 \mu \mathrm{mol} / \mathrm{l}(11.4 \mu \mathrm{g} / \mathrm{dl})$ and $0.13 \mu \mathrm{mol} / \mathrm{l}$ $(2.8 \mu \mathrm{g} / \mathrm{dl})$, respectively.

\footnotetext{
Original article Lin J-L et al. (2006) Environmental exposure to lead and progressive diabetic nephropathy in patients with type II diabetes. Kidney Int 69: 2049-2056
}

\section{OPG is prognostic of all-cause mortality and death from CVD in renal transplant recipients}

Cardiovascular disease (CVD) is a primary cause of graft failure and death in renal transplant recipients, but the factors influencing this relationship remain in part unknown. Hjelmesæth et al. prospectively studied the power of the serum proteins osteoprotegerin (OPG) and mannosebinding lectin (MBL)-which regulate bone resorption and trigger complement activation, respectively - to predict all-cause mortality and death from CVD in this group.

The study enrolled 173 consecutive renal transplant recipients who were free of diabetes 